\title{
Hydronium Detection in Hardened Concrete
}

\author{
Ana Martínez Ibernón ${ }^{1}$, José M. Gandía Romero ${ }^{1,2}$, Isabel Gasch ${ }^{1}$ and Manuel \\ Valcuende $^{2}$ \\ ${ }^{1}$ Instituto Interuniversitario de Investigación de Reconocimiento Molecular y Desarrollo Tecnológico \\ (IDM), Universitat Politècnica de València, Camino de Vera, s/n 46022 Valencia, Spain. E-mail: \\ anmarib@arqt.upv.es \\ ${ }^{2}$ Departamento de construcciones arquitectonicas. Universitat Politècnica de València, Camino de \\ Vera s/n, 46022 Valencia, España. E-mail: mvalcuen@csa.upv.es
}

\begin{abstract}
The monitoring of reinforced concrete structures allows us to detect the presence of aggressive agents into of the concrete matrix, on site and in a real time. These aggressive agents can produce the unexpected failure of the structures, thus discovering their presence is a fundamental aspect in the preservation of people safety and the durability of the structure. On the other hand, helps to reduce the cost of maintenance and repair operations, due to allow us to identify the problems faster, minimizing the intervention to be done. The present research paper was focused in the hydronium detection; the reduction of this species generates hydrogen, the hydrogen produces the embrittlement and cracking of the steel, which seriously compromises the right behaviour of the structure. The problem of hydrogen appears in industries such as ammonia processing or petrochemistry industries and nuclear power plants. All of them are industries in which a failure seriously compromises the welfare of people and the environment. Therefore, the detection of hydrogen penetration in reinforcement concrete structures in these cases are very interesting. In this study, with the purpose to detect the hydronium or hydrogen in the hardened concrete matrices is proposed the use of voltammetric sensor, which is part of a multisensory system called Electronic-Tongue. This is a preliminary study. The objective of these initial steps was to evaluate the detection capability of the sensor. Currently, have been designing a sequential test in order to evaluate the sensor in different partial hydrogen pressures with the purpose to develop mathematical models to the hydronium or hydrogen detection and quantification in hardened concrete matrix.
\end{abstract}

Keywords: Durability, Monitoring, Sensors, Hydrogen Embrittlement.

\section{Introduction}

The detection of hydronium and hydrogen availability variations in the reinforcement concrete structures is interesting due to the presence of $\mathrm{H}^{+} / \mathrm{H}_{2}$ are involve in reactions that produce the durability loss of the structures.

The reaction and molecular recombination of the hydrogen with metals have a greatly impact on their mechanical properties (C A Zapfpe, Member, Sims, and Aime, 1941; Mansilla, Brandaleze, and Ines, 2018; Schroeder and Müller, 2003). In the case of the steels we can classify the damage produced by the hydrogen in:

- High-temperature Hydrogen Attack (Decarburization), in this process the hightemperature $\left(<200^{\circ} \mathrm{C}\right)$ reaction of absorbed hydrogen with carbides in the steel results in the decarburization forming methane which can not spread due to the size of its molecules producing intergranular fissuring (Ovejero,2009). 
- Hydrogen-Induced Cracking (HIC), results from the penetration and molecular recombination of atomic hydrogen produced in the steel surface because of a corrosion process. This reaction generates high pressures which produce cracks or blisters in the steel (Ovejero,2009).

- Hydrogen Embrittlement (HE), produce the decrease of the metal ductility and load bering capability due to the absorption of hydrogen as atomic or molecular form by the metal. The hydrogen difuses to the metal grain boundaries producing pressure on the metal grains, this pressures can reach values that reduce the ductility and strength of the steel (Schroeder and Müller, 2003; Industrial Metallurgists, LLC).

In the case of reinforcement concrete structures these problems can produce the brittle failure of the structure (Ramón Zamora, 2018) which seriously threatens the people safety, also the failure generates high economical costs.

These phenomena affect in structures particularly in those industries that work with environments or substances that contain hydrogen. For instance: nuclear reactors, chemical industry, etc. Also, the hydrogen can be generated in structures where is used without any control of the potential the cathodic protection (impressed current) (Byrne, Norton, and Holmes, 2016; Enos, Williams, Clemeña, and Scully, 1998; Ishii, Seki, Fukute, and Ikawa, 1998).

There are other reactions where $\mathrm{H}_{2} / \mathrm{H}^{+}$compromise the reinforcement durability such as the carbonation of the concrete and chlorides attack.

In the carbonation of the concrete the $\mathrm{CO}_{2}$ penetrates reacting with the hydroxide ions and

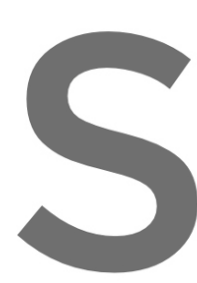
increasing $\left(\mathrm{H}_{3} \mathrm{O}^{+}\right)$activi passive layer destruction On the other hand, w place (Neville, Wharf,
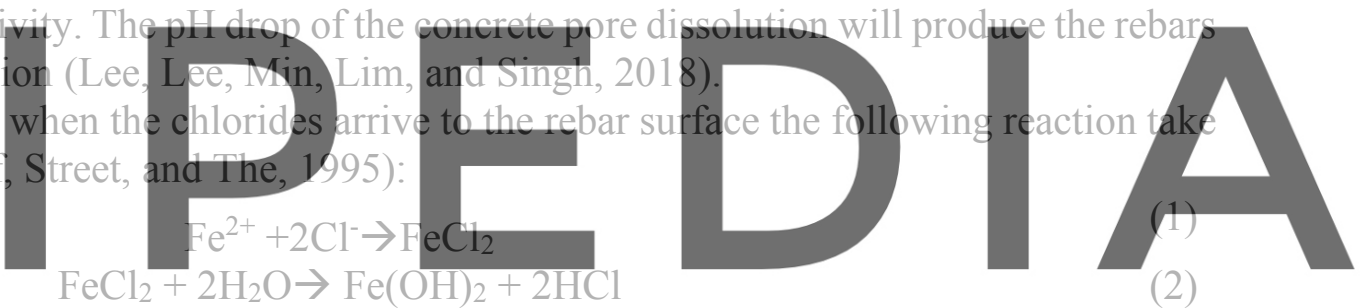

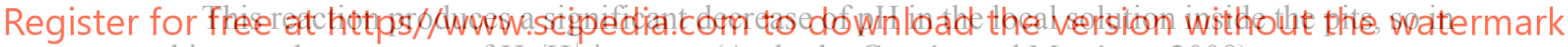
this area the presence of $\mathrm{H}_{2} / \mathrm{H}^{+}$increase (Andrade, Garcés, and Martínez, 2008).

As is widely known, concrete carbonation and chlorides attack produce the passive layer destruction and the active corrosion of reinforcements starts if thermodynamic conditions are favourable.

Therefore, the increase detection of the $\mathrm{H}_{2} / \mathrm{H}^{+}$can help us to avoid the problems related to the absorption of the hydrogen or hydronium in the steel and also to prevent the corrosion of the rebars when the carbonation of the concrete or the chlorides attack is produced.

With the purpose of preventing or controlling these phenomena will be effective use monitoring systems to control the conditions of the rebars embedded in the concrete and also identify the presence of aggressive substance into of the concrete such as $\mathrm{H}_{2} / \mathrm{H}^{+}$.

In this study is proposed the use of a novelty and promising monitoring system formed by cross-sensitivity voltammetric sensor and named Electronic Tongue (e-Tongue). These systems are widely used in the food industry being very effective (Bataller, 2001; Ramón Zamora, 2018).

In this monitoring system, a potential signal vary over time is applied on the sensors, producing the reduction or oxidation over the sensors surfaces of different electroactive species presents in the electrolyte, being recorded an electrical current response from each sensor. The 
reactions that produce these responses depend on the quantity of the electroactive species and the experimental conditions, such as the sensor material and the potential sweeping range. Therefore, depending on the agents of interest (oxygen, water, chlorides, $\mathrm{H}^{+} / \mathrm{H}_{2}$, etc.) the experimental conditions will be defined. Then, by means of multivariate analysis of the sensors response, can be developed forecasting and quantification mathematical models to modelling the presence of the interest substance in the hardened concrete matrix.

In this study was performed an initial evaluation of the Rh voltammetric sensors capability in order to detect variations in the couple hydronium/hydrogen inside of the hardened concrete.

These sensors form part of the novel multisensory system e-Tongue, which are currently under development. In a previous work was verified the capability of INOX voltammetric sensors to detect oxygen availability variations inside of the hardened concrete matrix (Martínez-Ibernón et al., 2020) which is going to form part of the e-Tongue.

\section{Materials and Methods}

\section{Concrete sample $(10 \mathrm{~cm}$ x10 $\mathrm{cm} \times 10 \mathrm{~cm})$ of water/cement ratio 0.4 was made, the composition of the concrete is specified in Table 1 .}

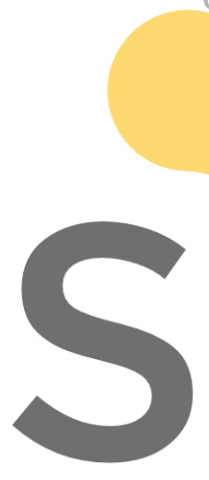

Table 1. Composition of the concrete.

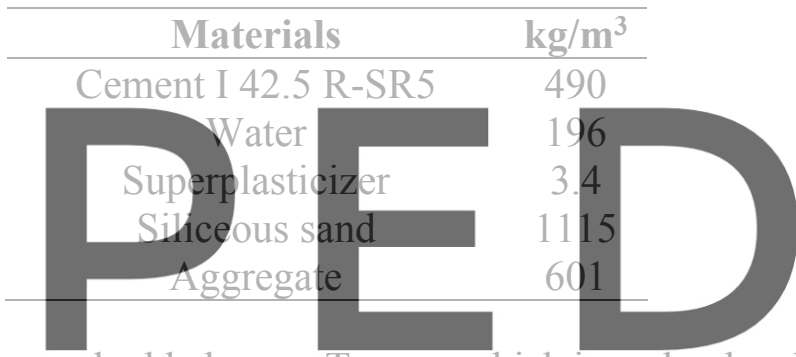

In the concrete sample was embedded one e-Tongue which is under development (Figure 1).

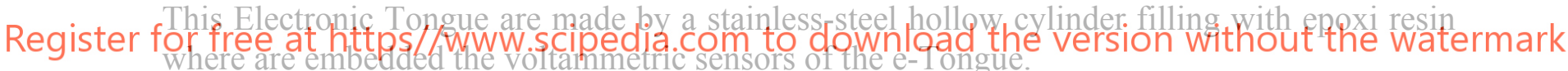

The purpose of this study is analysed the response of one of the sensors that forms the eTongue, this is the Rh voltammetric sensor, this are made with thread of this metal ( $1 \mathrm{~mm}$ of diameter and $2 \mathrm{~mm}$ of length).

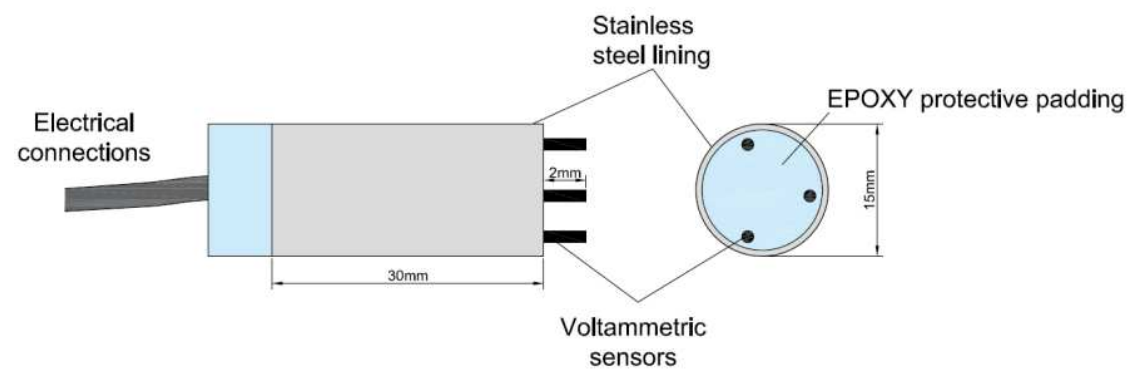

Figure 1. Electronic Tongue.

The samples were studied in two different conditions:

- State 1: Concrete in atmospheric conditions (dry conditions). 
- State 2: Concrete saturated with water. In order to ensuring the higher quantity penetration of water inside of the concrete matrix, the samples were inserted in a deposit with an airtight lid. In this deposit was reached the vacuum conditions by means of a pump, these conditions were kept during three hours. Then was let the entrance of water until the samples were totally submerged. After two hours the vacuum was broken and the specimens were kept submerged in water as show the Figure 2.

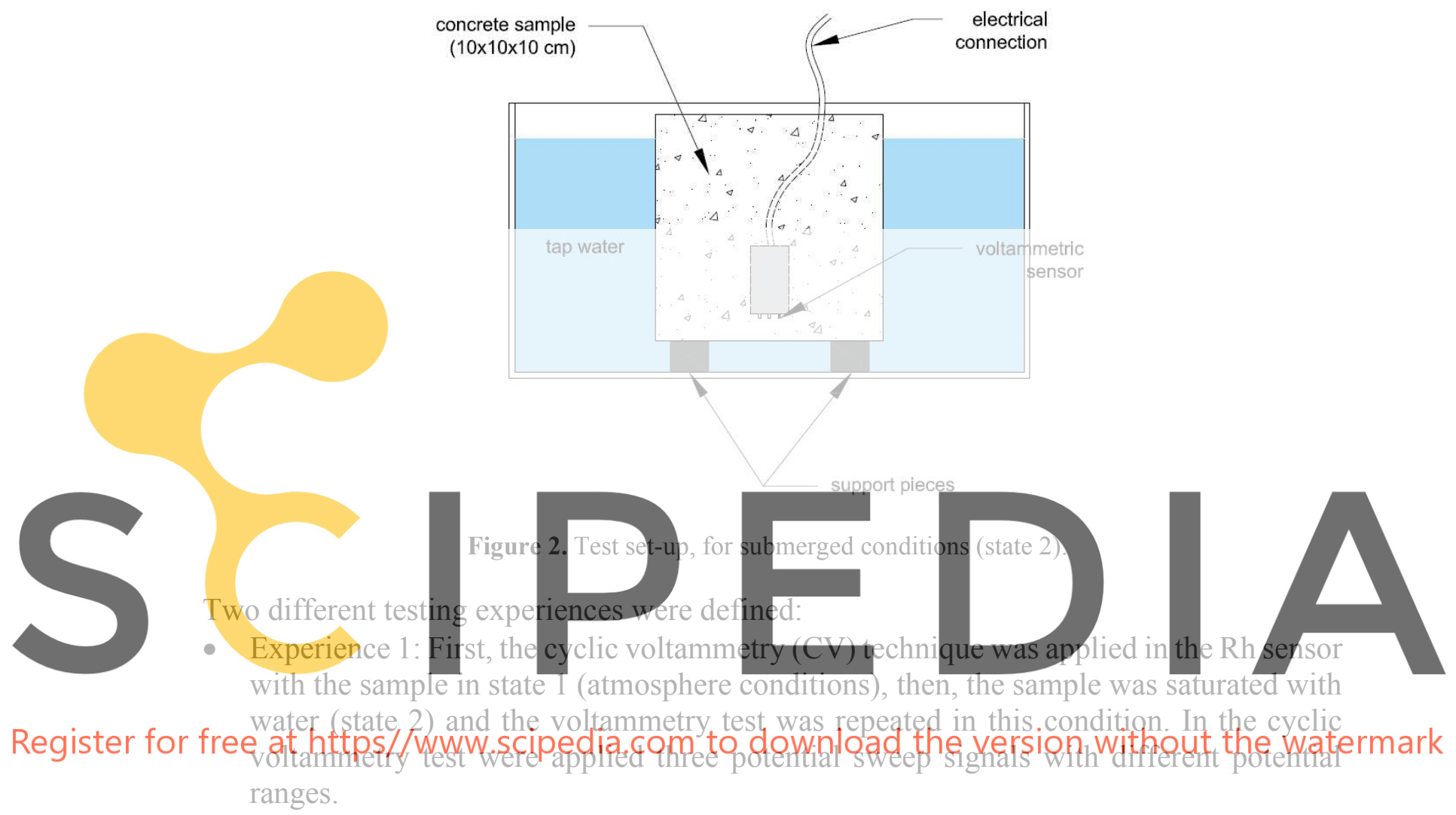

- Experience 2: In this experience, was used a high amplitude cathodic potential pulse (-1.6V amplitude signal), during $3 \mathrm{~min}$, to ensure the generation of atomic and molecular hydrogen. The samples in this experience were in water saturated conditions (state 2). The test sequence was: Previously to apply the potential pulse was tested the sample with a $\mathrm{CV}$, in order to define a baseline of the system conditions, then, the hydrogen generation pulse was applied, finally a cyclic voltammetry was applied. The experience was repeated for two different potential sweeps.

The electrochemical techniques were applied with three electrodes and Autolab PGSTAT10 equipment was used. Specifically, these three electrodes were:

- Reference electrode: a saturated calomel electrode (SCE).

- Counter electrode: Stainless steel lining (Figure 1).

- Working electrode: $\mathrm{Rh}$ voltammetric sensor.

The experiences defined allowed us to check the presence of peaks related to reactions associated with the hydronium and the hydrogen. It was possible through the comparation of 
the results with the voltagrams for alkaline systems showed in the paper Jaksic, Johansen, and Tunold, (1994).

\section{Results and Discussion}

The Rh voltammetric sensors used in the Electronic Tongue are capable to detect the presence of hydronium and hydrogen in the concrete matrix. As we can see in the Figure 3, the morphology of the electric current density curve, obtained with the embedded sensor in the conditions of the state 2, is similar to the curve obtained in an alkaline system in dissolution (Jaksic, Johansen, and Tunold, 1994), we can identify the same peaks associated with reactions that involve $\mathrm{H}^{+} / \mathrm{H}_{2}$.

However, when the samples are in non-saturated conditions (state 1), meaning the water availability inside of the hardened concrete is very low, the peaks related to the hydronium and hydrogen do not appear (Figure 4).
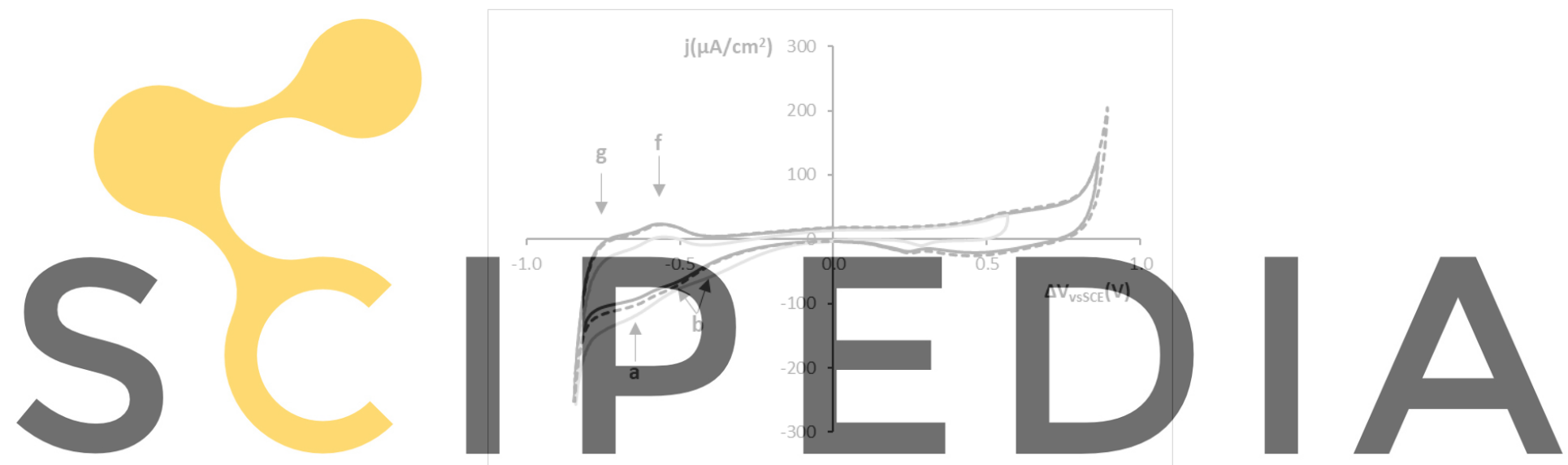

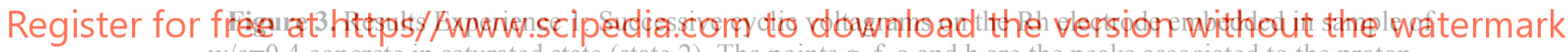
$\mathrm{w} / \mathrm{c}=0.4$ concrete in saturated state (state 2 ). The points $\mathrm{g}, \mathrm{f}, \mathrm{a}$ and $\mathrm{b}$ are the peaks associated to the proton reactions as defined by Jaksic, Johansen, and Tunold, (1994). 


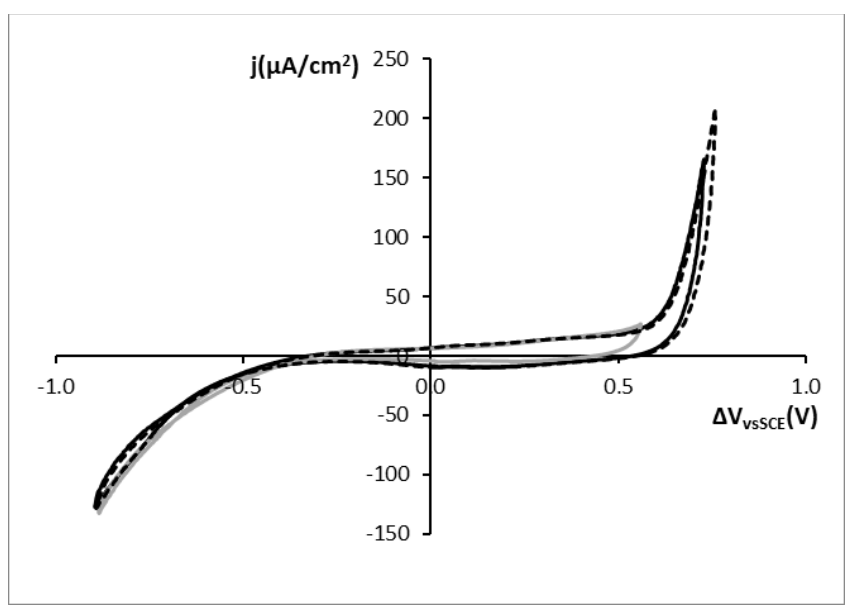

Figure 4. Results of Experience 1: Successive cyclic voltammograms on the Rh electrode embedded in sample of $\mathrm{w} / \mathrm{c}=0.4$ concrete in atmospheric state (state 1 ).

On the other hand, after to apply a high amplitude potential pulse with negative value, the generation of hydrogen was assured. The amplitude of the pulse was $-1.6 \mathrm{~V}$, at this potential and for $\mathrm{pH}$ similar to the concrete $(\mathrm{pH} \approx 12.5)$, water reduction is already taking place, in this reaction $\mathrm{H}_{2}$ is generated.
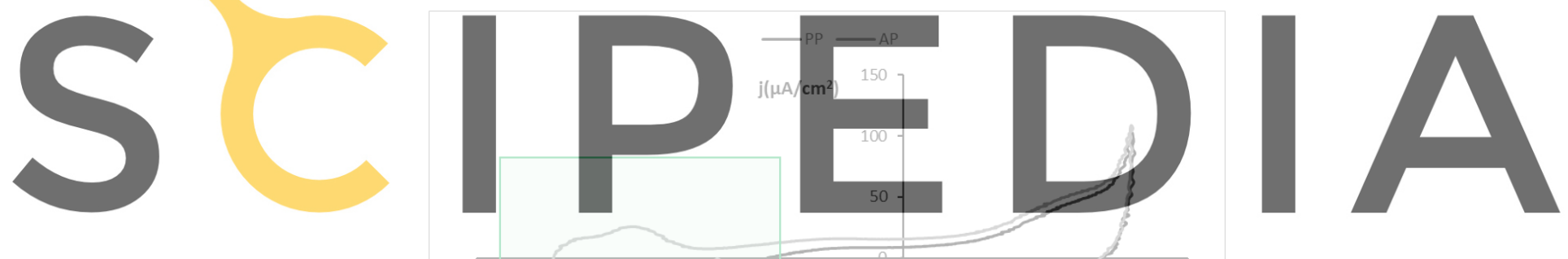

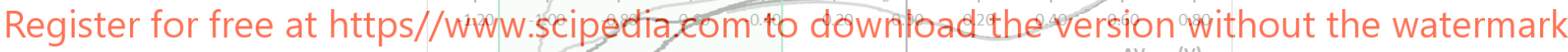
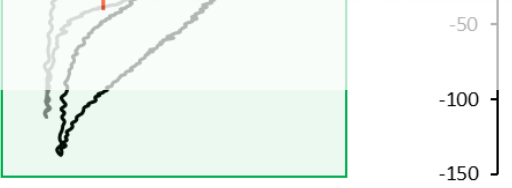

Figure 5. Results of Experience 2: Line black: Voltagram of the system previously cathodic pulse (PP). Line grey: Voltagram of the system after cathodic pulse (AP). Green square: Indicates the zone where the response is associated to reactions where are involved $\mathrm{H}+/ \mathrm{H} 2$.

The Figure 5 shows how after to apply the cathodic pulse (AP), the peaks associated with the desorption and adsorption of the $\mathrm{H}^{+} / \mathrm{H}_{2}$ risen. The increasement of the desorption peaks causes the upward movement of the curve, due to in this potential range the mainly reaction is with $\mathrm{H}^{+} / \mathrm{H}_{2}$, whereas previously to the potential pulse application the mainly reaction was the water reduction.

If the test is repeated doing several sweep cycles in each situation (AP and PP), we can see how in the PP situation (previously to the cathodic pulse application) (Figure 6 a) there are a negligible change from initial sweep. However the results obtained when the cathodic potential 
pulse is applied $(-1.6 \mathrm{~V})$ shows the increasement of the total electric density current as cycles are done (Figure 6 b).

This demonstrates that the $\mathrm{Rh}$ electrode has a region of potential sensitive to the generation and adsorption/desorption processes of $\mathrm{H}^{+} / \mathrm{H}_{2}$. Therefore, this sensor could be used in hardened concrete matrix to detect the species involved in the redox couple.

a)

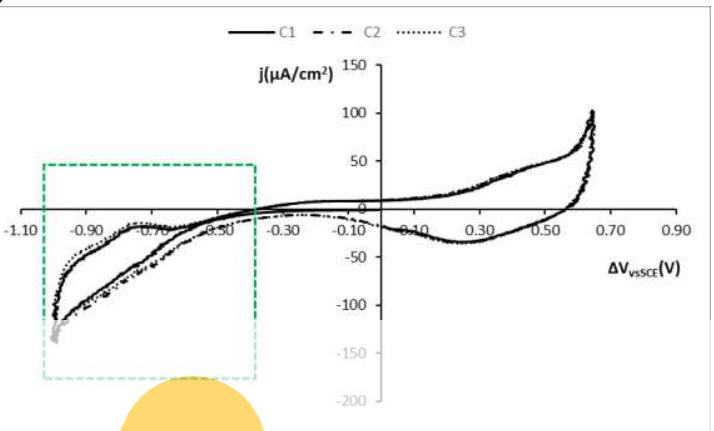

b)

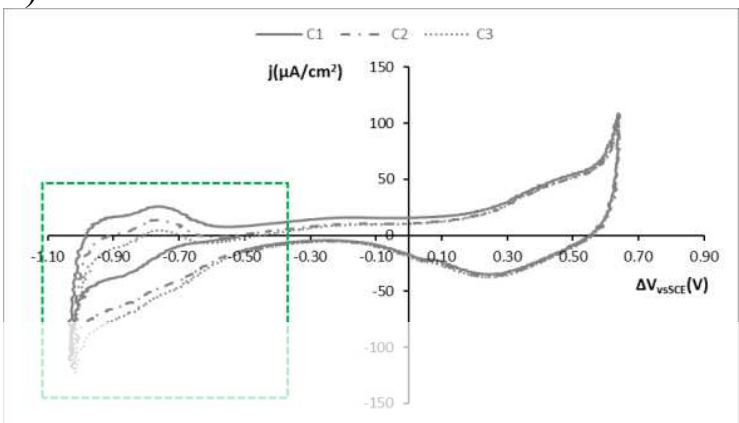

Figure 6. Results of Experience 2: a) Voltagram of the system previously cathodic pulse (PP). b) Voltagram of the system after cathodic pulse (AP). C1, C2 and C3 are successive cycles. The zone under examination are pointed with the green rectangle.

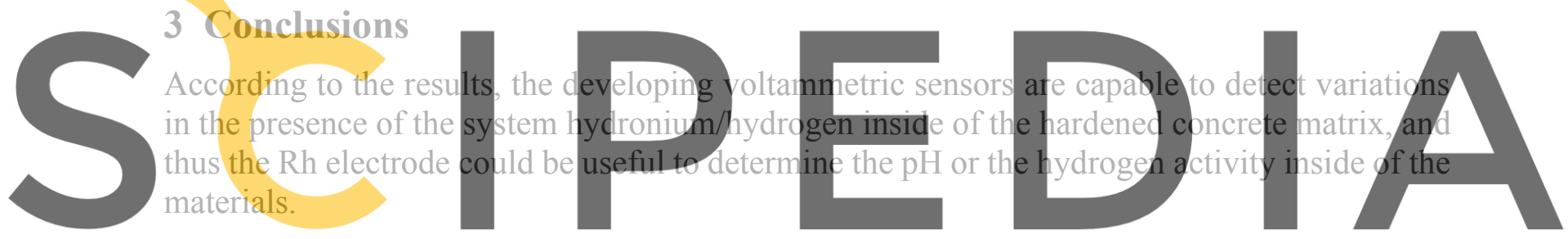

Acknowledgements

Register for free at https//www.scipedia.com to download the version without the watermark doctoral scholarship granted to Ana Martínez Ibernón (FPU 16/00723). Also, to the Universitat Politècnica de València for the financial support in the project "Ayudas a Primeros Proyectos de Investigación (PAID-06-18)".

\section{ORCID}

A. Martínez Ibernón: https://orcid.org/0000-0003-2136-5650

J.M. Gandía Romero: https://orcid.org/0000-0003-0257-3286

I. Gasch: https://orcid.org/0000-0001-7036-4481

M. Valcuende: https://orcid.org/0000-0002-9967-1554

\section{References}

Andrade, C., Garcés, P. and Martínez, I. (2008). Galvanic currents and corrosion rates of reinforcements measured in cells simulating different pitting areas caused by chloride attack in sodium hydroxide. Corrosion Science, 50(10), 2959-2964. https://doi.org/10.1016/j.corsci.2008.07.013

Bataller, R. (2001). Fabricación y puesta a punto de una nariz electrónica húmeda para la detección de gases y vapores. P.h.D. Thesis, Universitat Politècnica de València, València, Spain,.

Byrne, A., Norton, B. and Holmes, N. (2016). State-of-the-art review of cathodic protection for reinforced concrete structures. Magazine of Concrete Research, 68(13), 664-677. https://doi.org/10.1680/jmacr.15.00083 
C A Zapfpe, B. Y., Member, J., Sims, C. E. and Aime, M. (1941). Metals Technology, 1941, Vol. VIII - August 1941 - T.P. 1307 - Hydrogen Embrittlement, Internal Stress and Defects in Steel, 1307(1307). Retrieved from http://library.aimehq.org/library/books/Metals Technology, 1941, Vol. VIII/T.P. 1307.pdf

Enos, D. G., Williams, A. J., Clemeña, G. G. and Scully, J. R. (1998). Impressed-Current Cathodic Protection of Steel-Reinforced Concrete Pilings: Protection Criteria and the Threshold for Hydrogen Embrittlement. Corrosion, 54(5), 389-402. https://doi.org/10.5006/1.3284867

Hydrogen Embrittlement of Steel - Industrial Metallurgists. (2018, 9 julio). https://www.imetllc.com/trainingarticle/hydrogen-embrittlement-steel/

Ishii, K., Seki, H., Fukute, T. and Ikawa, K. (1998). Cathodic protection for prestressed concrete structures. Construction and Building Materials, 12(2-4), 125-132.

Jaksic, M. M., Johansen, B. and Tunold, R. (1994). Electrochemical behaviour of rhodium in alkaline and acidic solutions of heavy and regular water. International Journal of Hydrogen Energy, 19(4), 35-51. https://doi.org/10.1016/0360-3199(94)90064-7

Lee, H. M., Lee, H. S., Min, S. H., Lim, S. and Singh, J. K. (2018). Carbonation-induced corrosion initiation probability of rebars in concretewith/without finishing materials. Sustainability (Switzerland), 10(10). https://doi.org/10.3390/su10103814

Mansilla, G. A., Brandaleze, E. and Ines, M. (2018). Interactions and effects of hydrogen on high strength steels I NTERACTIONS AND EFFECTS OF HYDROGEN ON HIGH STRENGTH STEELS Graciela A . Mansilla , Elena Brandaleze, Mariano N . Inés, (February 2019).

Martínez-Ibernón, A., Roig-Flores, M., Lliso-Ferrando, J., Mezquida-Alcaraz, E. J., Valcuende, M. and Serna, P. (2020). Influence of cracking on oxygen transport in UHPFRC using stainless steel sensors. Applied Sciences (Switzerland), 10(1). https://doi.org/10.3390/app10010239

Neville, A., Wharf, G., Street, H. and The, U. K. (1995). Chloride attack of reinforced concrete : an overview. pag 07 y 08 dano por hidrogeno-ovejero garcia.pdf. (n.d.).

Ramón Zamora, J. E. (2018). Sistema de Sensores Embebidos para Monitorizar la Corrosión en Estructuras de

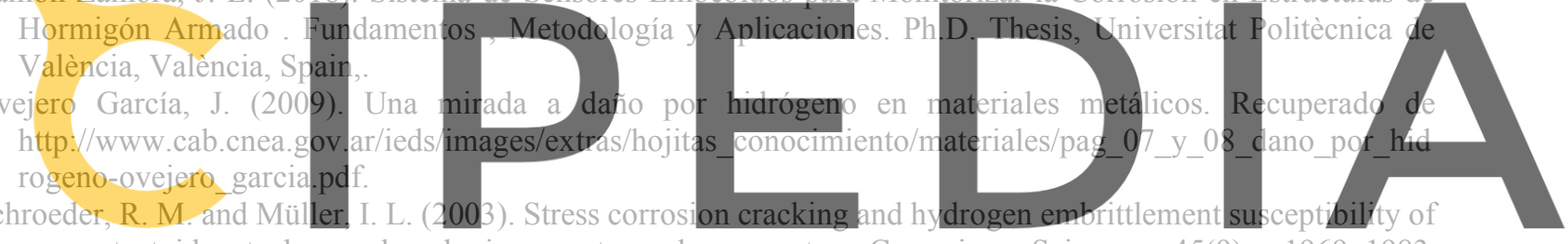

an eutectoid steel employed in prestressed concrete. Corrosion Science, 45(9), 1969-1983.

Register for free at https//W/WWW.scipedia.com to download the version without the watermark 